\title{
PENGARUH SCHOOL CLIMATE DAN PROCEDURAL JUSTICE TERHADAP CITIZENSHIP BEHAVIOR TOWARD ENVIRONMENT SISWA SMA
}

\author{
Yulianita Tri Jayanti' ${ }^{1}$ I Made Putrawan ${ }^{2}$, Refirman Dj $^{3}$ \\ ${ }^{1}$ Student of Biology Education Departement of State University of Jakarta \\ ${ }^{2}$ Environmental Education Departement of State University of Jakarta \\ ${ }^{3}$ Biologi Education Departement of State University of Jakarta \\ email: Yuliatj24@gmail.com
}

\begin{abstract}
ABSTRACK
Environmental destruction that occurs in Indonesia is increasing due to weak awareness behavior in protecting the environment. One of the efforts that can be made with citizenship behavior toward environment. This study aims to determine the influence of school climate and procedural justice on citizenship behavior toward environment. The method used is a survey method through causal studies and analyzed by path analysis. This research was conducted towards 70 students in SMAN 68 Jakarta in the odd semester of the 2020/2021 school year. The result of relianility coefficient calculation of citizenship behavior toward environment was 0.802, procedural justice was 0.786 , and school climate was 0.930. The results showed that school climate had a significant direct effect on procedural jsutice, procedural justice had a significant direct effect on citizenship behavior toward environment, school climate had a significant direct effect on citizenship behavior toward environment, and obtained good procedural justice results as a mediator variable between school climate and citizenship behavior toward environment in students
\end{abstract}

Keyword : Path Analysis, School climate, Procedural Justice, Citizenship Behavior Toward Environment, Student 


\section{PENDAHULUAN}

Permasalahan lingkungan di Indonesia mengalami permasalahan yang kompleks dan juga serius. Hal ini karena meningkatnya pertumbuhan penduduk disertai kemajuan pembangunan dan pemanfaatan sumber daya alam untuk perekonomian, maka tak sedikit yang menimbulkan dampak negatif yaitu perusakan lingkungan (Zairin, 2005). Menurut Undang - Undang No 32 Tahun 2009, perusakan lingkungan hidup adalah kegiatan yang dapat merubah secara langsung maupun tidak kondisi fisik atau hayatinya hingga melebihi batas kriteria baku perusakan lingkungan.

Peningkatan perusakan lingkungan juga diperburuk dengan lemahnya kesadaran masyarakat dalam pengelolaan sampah dan kurangnya kesadaran untuk membuang sampah pada tempatnya. Meskipun teknologi semakin berkembang, akar permasalahan lingkungan adalah perilaku manusia. Permasalahan lingkungan ini akan terus berlanjut bila minimnya kesadaran manusia untuk bergerak menjaga lingkungan. Perlu adanya keseimbangan antara manusia dan alam untuk kelestarian lingkungan.

Pendidikan dapat dijadikan sarana yang mendorong kesadaran dan perubahan perilaku manusia untuk bisa peduli terhadap lingkungan sejak dini. Dengan pendidikan, dapat mempengaruhi perubahan perilaku yang lebih rasional dalam menanggapi permasalahan pada lingkungan (Putrawan, 2015). Perilaku yang dapat ditanamkan kepada siswa sebagai generasi penerus yaitu perilaku bijak terhadap lingkungan (citizenship behavior toward environment) yang merupakan perilaku positif siswa secara sadar diluar kewajiban yang sudah tertulis untuk menjaga lingkungan.

Citizenship behavior toward environment yang dimiliki siswa dapat mengembangkan komitmen kesadaran peduli lingkungan lebih dari kewajiban yang telah ditetapkan sekolah. Perilaku bijak lingkungan dapat meminimalkan kegiatan perusakan lingkungan. Perilaku tersebut dapat terlihat Ketika seseorang melakukan pengelolaan sampah, kemasan ramah lingkungan, mendaur ulang, dan bijak menggunakan listrik (Putrawan, 2017). Citizenship behavior toward environment ini 
juga sebagai extra-role behavior yang berdampak baik dalam kontribusi siswa untuk menjaga lingkungan (Handoyo, 2012).

Berdasarkan penelitian yang dilakukan oleh E.M. Dijkstra \& M.J. Goedhart menyatakan bahwa citizenship behavior dapat dipengaruhi oleh iklim sekolah (school climate). Cohen berpendapat, school climate mengacu pada pengalaman kehidupan di sekolah yang berkaitan dengan norma dan nilai, hubungan interpersonal dan interaksi sosial, dan proses organisasi, struktur dan budaya. School climate dapat dikatakan sebagai pandangan siswa terhadap lingkungan sekolah, termasuk pada keadaan sekolah, interaksi di sekolah, dan kualitas pembelajaran di sekolah.

Keadilan juga merupakan faktor penting yang dapat mempengaruhi citizenship behavior, hal ini sesuai dengan pernyataan yang diungkapkan McShine \& Glinow bahwa perilaku adil dapat meningkatkan emosi dan motivasi, dan perilaku seseorang. Procedural justice memiliki konsekuensi emosional. Menurut Murphy dan Tyler (2008) dalam penelitiannya, mengungkapkan bahwa persepsi manusia dengan kondisi procedural justice yang tinggi akan meningkatkan emosional yang positif yaitu kebahagiaan. DeCremer dan Stouten (2005) menjelaskan, bahwa orang dengan kondisi procedural justice yang baik akan memiliki emosi positif lebih kuat dibanding dengan orang yang kondisi procedural justice yang buruk. Maka dari itu procedural justice yang baik bisa mendukung perilaku bijak siswa terhadap lingkungan (Citizenship behavior toward environtmen)

Berdasarkan integrative model of organizational behavior yang dikemukakan oleh Colquitt, bahwa Citizenship behavior toward environment merupakan salah satu bagian dari job performance, yang diartikan sebagai outcomes dari diri seseorang. Job performance tersebut dapat dipengaruhi oleh beberapa factor, diantaranya school climate yang merupakan bagian dari organizational culture dan Justice yang merupakan Individual Mechanism. 


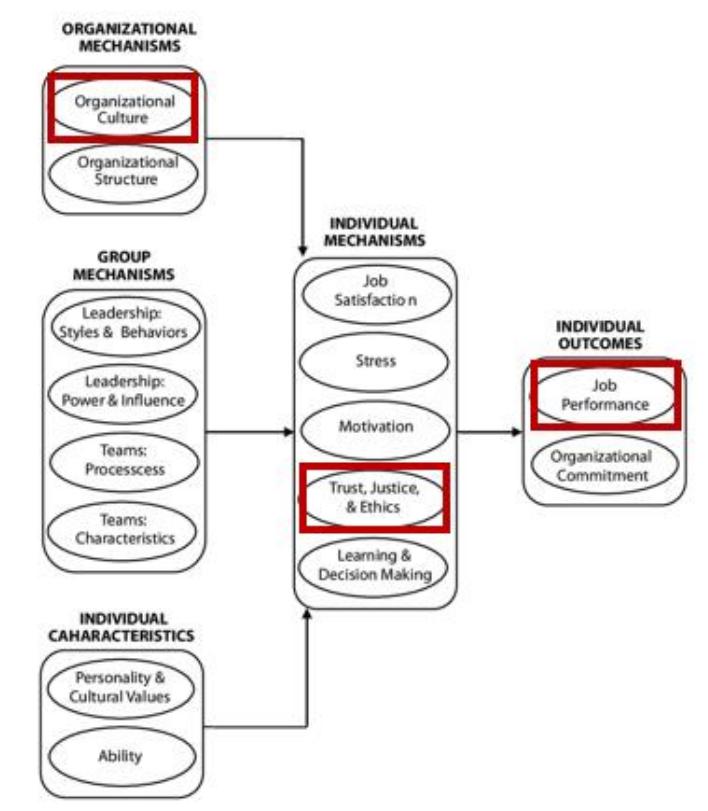

Gambar 1. Integrative model of organizational culture (Colquitt et al 2017)

Oleh karena itu, penelitian ini dilakukan untuk mengetahui (1) Apakah school climate berpengaruh langsung terhadap procedural justice? (2) Apakah procedural justice perbengaruh langsung terhadap citizenship behavior toward environment? (3) Apakah school climate berpengaruh langsung terhadap citizenship behavior toward environment? (4) Apakah school climate berpengaruh tidak langsung terhadap citizenship behavior toward environment melalui procedural justice?

\section{METODOLOGI PENELITIAN}

Metode yang digunakan adalah metode survey yang bersifat kausal untuk mengetahui sebab akibat dari setiap variable. Penelitian yang dilakukan merupakan jenis penelitian kuantitatif dengan menggunakan teknik analisis jalur. Penggunaan teknik ini untuk mengetahui pengaruh langsung atau tidak langsung antara variable eksogen dan endogen. Pada penelitian ini terdapat variable X1 (school climate) dan 
variable X2 (procedural justice) yang merupakan variable eksogen, lalu variable X3 (citizenship behavior toward environment) yang merupakan variable endogen.

Penentuan populasi dan sampling penelitian ini dengan menggunakan teknik pemilihan sample bertingkat (multi-stage random sampling). Populasi penelitian yang akan dilakukan adalah seluruh siswa di Sekolah Menengah Atas (SMA) Negeri di provinsi DKI Jakarta. Dengan teknik purposive sampling terpilihlah SMA di kota Jakarta Pusat. Lalu, dari seluruh kecamatan yang terdapat di kota Jakarta Pusat, terpilih kecamatan Senen dengan teknik cluster random sampling. Dilanjutkan kembali dengan cluster random sampling sehingga terpilih SMAN 68 Jakarta di kecamatan tersebut. Dari seluruh siswa SMAN 68 Jakarta, dipilih 3 kelas sebagai reponden dengan pemilihan sampel menggunakan teknik simple random sampling. Dalam pelenilian ini digunakan 35 siswa sebagai sampel uji coba, dan 70 siswa sebagai sampel. Sampel selanjutnya dihitung dengan menggunakan rumus McClave (2011), jika didapatkan nilai $\mathrm{SE} \leq 2,0$ maka disimpulkan bahwa data homogen dan representatif. Hasil perhitungan di dapat nilai SE $1.02<2.0$ yang menunjukkan data sampel sudah homogen dan representative.

\section{HASIL DAN PEMBAHASAN}

Hipotesis penelitia diuji dengan menggunakan uji $\mathrm{F}$ dan hasil sebagai berikut:

\section{a. Pengaruh Langsung School Climate (X1) terhadap Procedural Justice (X2)}

Dari data hasil perhitungan model persamaan regresi school climate (X1) terhadap procedural justice $(\mathrm{X} 2)$, didapat konstanta regresi $\mathrm{a}=46.120$ dan koefisien regresi $b=0.551$. Sehingga model persamaan regresi adalah $\hat{X} 2=46.120+0.551$ X1 Dilakukan pengujian signifikansi sebelum model persamaan regresi tersebut dianalisis. Dari perhitungan uji signifikansi menggunakan ANOVA didapat nilai $\mathrm{F}$ hitung $=24.989$, dan nilai $\mathrm{F}$ tabel $(0.05: 70)=3.98, \mathrm{~F}_{\text {tabel }}(0.01: 70)=7.01$, F tabel $(0.001: 70)$ $=11.8$, sehingga $\mathrm{F}$ hitung $>\mathrm{F}$ yang berarti model $\hat{\mathrm{X}} 2=46.120+0.551 \mathrm{X} 1$ adalah signifikan. Dilanjutkan perhitungan hasil uji linearitas didapat nilai $\mathrm{F}$ hitung $=0.965$, 
sedangkan nilai $\mathrm{F}$ tabel $(28 / 40)=1.76$, dikarenakan $\mathrm{F}$ hitung $<\mathrm{F}$ tabel, dapat disimpulan model regresi $\hat{\mathrm{X}} 2=46.120+0.551$ X1adalah Linier

Pengujian koefisien jalur X1 terhadap X2 dapat dilihat pada tebel berikut:

Tabel 1. Uji Analisis Jalur X1 terhadap X2

\begin{tabular}{|c|c|c|c|c|c|c|c|c|c|}
\hline & \multirow[t]{2}{*}{ Model } & \multicolumn{2}{|c|}{$\begin{array}{c}\text { Unstandardized } \\
\text { Coefficients }\end{array}$} & \multirow{2}{*}{$\begin{array}{c}\text { Standardized } \\
\text { Coefficients } \\
\text { Beta }\end{array}$} & \multirow[t]{2}{*}{$\mathrm{t}$} & \multirow{2}{*}{$\begin{array}{l}\mathrm{t} \text { tabel } \\
(0.05)\end{array}$} & \multicolumn{3}{|c|}{ Correlations } \\
\hline & & $\mathrm{B}$ & Std. Error & & & & Zero-order & Partial & Part \\
\hline \multirow[b]{2}{*}{1} & (Constant) & 46.120 & 11.384 & & 4.051 & \multirow[b]{2}{*}{1.667} & & & \\
\hline & $\begin{array}{l}\text { School } \\
\text { climate }\end{array}$ & .551 & .110 & .518 & $4.999 *$ & & .518 & .518 & .518 \\
\hline
\end{tabular}

a. Dependent Variable: Procedural Justice

Hasil perhitungan analisis jalur (path analysis) X2 atas X1, diperoleh hasil Phi $_{21}=0.518$ dengan $\mathrm{t}$ hitung $(4.999)>\mathrm{t}$ tabel $(0.05,68)=1.667$ yang berarti bahwa terdapat pengaruh langsung antara school climate terhadap procedural justice yang signifikan. Dengan nilai dari zero-order $(0.518)=$ nilai partial $(5.18)$.

\section{b. Pengaruh Langsung Procedural Justice (X2) terhadap Citizenship Behavior Toward Environment (X3)}

Dari data hasil perhitungan model persamaan regresi procedural justice (X2) terhadap citizenship behavior toward environment $(\mathrm{X} 3)$, didapat konstanta regresi $\mathrm{a}=$ 41.525 dan koefisien regresi $b=0.586$. sehingga model persamaan regresi adalah $\hat{X} 3$ $=41.525+0.586 \times 2$.

Dari perhitungan uji signifikansi menggunakan ANOVA didapat nilai $\mathrm{F}$ hitung $=28.349$, dan nilai $\mathrm{F}$ tabel $=3.98, \mathrm{~F}$ tabel ${ }_{(0.01: 70)}=7.01, \mathrm{~F}$ tabel $(0.001: 70)=11.8$ ,sehingga $\mathrm{F}$ hitung > F yang berarti model $\mathrm{X} 3=41.525+0.586 \mathrm{X} 2$ adalah signifikan. Dilanjutkan perhitungan uji Linearitas, didapat nilai $\mathrm{F}$ hitung $=0.750$, sedangkan $\mathrm{F}$ 
tabel $_{(18 / 50)}=1.81$, sehingga $\mathrm{F}$ hitung $<\mathrm{F}$ tabel, dapat disimpulan model regresi $\hat{\mathrm{X}} 3=$ $41.525+0.586 \times 2$ adalah Linier.

Pengujian koefisien jalur X2 terhadap X3 dapat dilihat pada tebel berikut:

Tabel 2. Uji Analisis Jalur X2 terhadap X3

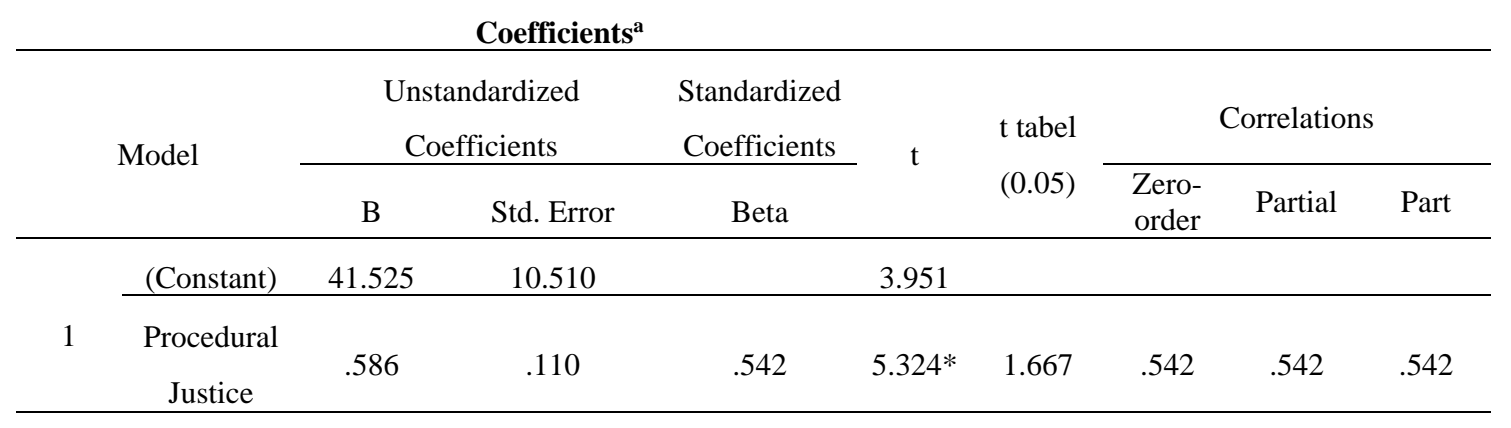

a. Dependent Variable: Citizenship Behavior Toward Environment

Dari hasil perhitungan analisis jalur (path analysis) X3 atas X2, diperoleh hasil Phi $32=0.542$ dengan $t_{\text {hitung }}(5.342)>t$ tabel $(0.05,68)=1.667$ yang berarti bahwa terdapat pengaruh langsung antara procedural justice terhadap citizenship behavior toeard enviroonment yang signifikan. Dengan nilai Zero-order $(0.542)=$ nilai partial $(0.542)$.

\section{c. Pengaruh Langsung School Climate (X1) terhadap Citizenship Behavior Toward Environment (X3)}

Dari data hasil perhitungan model persamaan regresi school climate (X1) terhadap citizenship behavior toward environment (X3), didapat konstanta regresi $\mathrm{a}=$ 21.111 dan koefisien regresi $b=0.740$, sehingga model persamaan regresi adalah $\hat{X} 3$ $=21.111+0.740 \mathrm{X} 1$, dilakukan pengujian signifikansi sebelum model persamaan regresi tersebut dianalisis.

Dari perhitungan uji signifikansi dengan ANOVA didapat nilai $\mathrm{F}$ hitung = 50.227 , dan nilai $\mathrm{F}$ tabel $=3.98, \mathrm{~F}$ tabel $(0.01: 70)=7.01, \mathrm{~F}$ tabel $(0.001: 70)=11.8$, sehingga $\mathrm{F}$ hitung $>\mathrm{F}$ yang berarti model $\hat{\mathrm{X}} 3=21.111+0.740 \mathrm{X} 1$ adalah signifikan. Dilanjutkan perhitungan uji linearitas, nilai $\mathrm{F}$ hitung $=1.019$, sedangkan F tabel $(28 / 40)$ 
$=1.760$, sehingga $\mathrm{F}$ hitung $<\mathrm{F}$ tabel, dapat disimpulan model regresi $\hat{\mathrm{X}} 3=21.111+$ $0.740 \times 1$ adalah Linier.

Pengujian koefisien jalur X1 terhadap X3 dapat dilihat pada tebel berikut:

Tabel 3. Uji Analisis Jalur X1 terhadap X3

\begin{tabular}{|c|c|c|c|c|c|c|c|c|c|}
\hline & \multirow{2}{*}{ Model } & \multicolumn{2}{|c|}{$\begin{array}{c}\text { Unstandardized } \\
\text { Coefficients }\end{array}$} & \multirow[t]{2}{*}{$\begin{array}{l}\text { Standardized } \\
\text { Coefficients }\end{array}$} & \multirow{2}{*}{$\mathrm{T}$} & \multirow{2}{*}{$\begin{array}{l}t \text { tabel } \\
(0.05)\end{array}$} & \multicolumn{3}{|c|}{ Correlations } \\
\hline & & B & $\begin{array}{l}\text { Std. } \\
\text { Error }\end{array}$ & & & & $\begin{array}{l}\text { Zero- } \\
\text { order }\end{array}$ & Partial & Part \\
\hline \multirow[b]{2}{*}{1} & (Constant) & 21.111 & 10.779 & & 1.959 & & & & \\
\hline & $\begin{array}{l}\text { School } \\
\text { climate }\end{array}$ & .740 & .104 & .652 & $7.087 *$ & 1.667 & .652 & .652 & .652 \\
\hline
\end{tabular}

a. Dependent Variable: Citizenship Behavior

Dari hasil perhitungan analisis jalur (path analysis) X3 atas X1, diperoleh hasil Phi31 $=0.652$ dengan $t$ hitung $(7.087)>t$ tabel $(0.05,68)=1.667$ yang berarti bahwa terdapat pengaruh langsung antara school climate terhadap citizenship behavior toward enviroonment yang signifikan. Dengan nilai Zero-order $(0.652)=$ nilai partial $(0.652)$.

\section{d. Pengaruh Tidak Langsung School Climate (X1) terhadap Citizenship Behavior Toward Environment (X3) melalui Procedural Justrice (X2)}

Pengaruh school climate (X1) terhadap citizenship behavior toward environment (X3) melalui procedural justice (X2) dapat dihitung dengan menggunakan rumus sebagai berikut :

Phi31.2 $=\left(\mathrm{Phi}_{21}\right)(\mathrm{Phi} 32)$

Phi $_{31.2}=(0.518)(0.542)$

Phi $_{31.2}=(0.281)$

Berdasarkan hasil perhitungan diperoleh thitung $=2.395$ hal ini menandakan $\mathrm{t}_{\text {hitung }}=2.395>\mathrm{t}_{\text {tabel }}=1.667$ Hasil ini menandakan terdapat pengaruh tidak langsung 
antara school climate terhadap citizenship behavior toward environment melalui procedural justice secara signifikan.

Dari semua hipotesis yang dihasilkan nilai Phi total effect diperoleh dari Phi3.1 $=0.652$ dengan Phi $31.2=0.281$, sehingga didapat hasil 0.183. Dilanjutkan dengan perhitungan dan didapat thitung $=1.991$ dengan nilai $t_{\text {tabel }}=1.667$. Sehingga $t_{\text {hitung }}>t$ tabel yang artinya terdapat pengaruh antar variabel yang diujikan secara signifikan.

Hasil semua hipotesis dapat dibuat model empirik sebagai berikut :

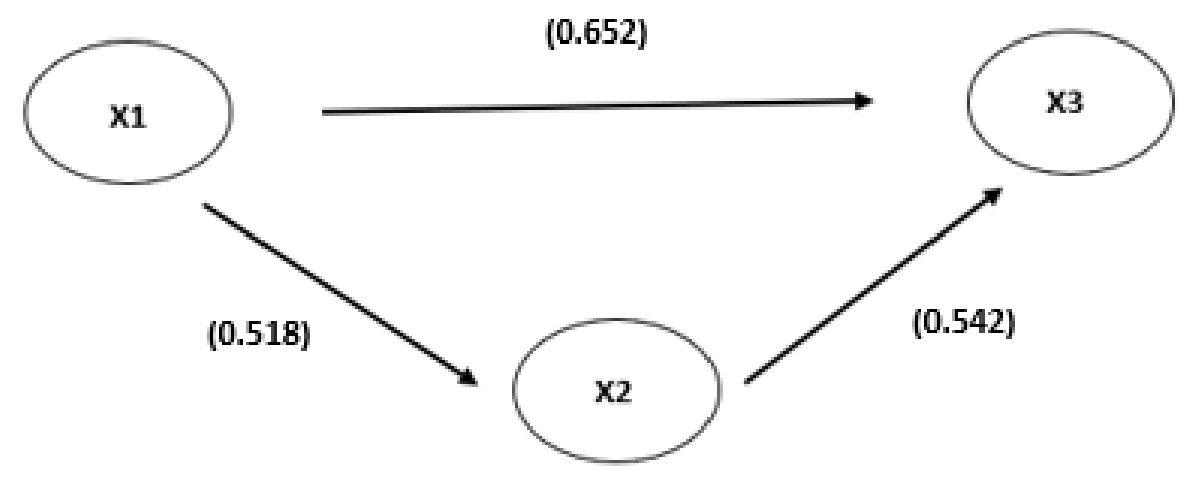

Keterangan :

X1 : School climate

X2 : Procedural Justice

X3 : Citizenship Behavior Toward Environment

Berdasarkan hasil penelitian yang dilakukan, hasil dari pengujian hipotesis pertama menunjukkan terdapat pengaruh langsung antara school climate terhadap procedural justice yang dimiliki siswa secara signifikan. Hal ini membuktikan secara empirik dan teoritik bahwa dengan school climate yang diterima siswa sangat positif, maka akan membuat procedural justice siswa yang baik

Dengan school climate yang baik akan bermanfaat pada pembelajaran kooperatif, prestasi akademik, perkembangan siswa, rasa hormat, kepercayaan, dan persepsi 
keadilan (Ghaith, 2013). Faktor dari school climate seperti kepemimpinan, profesional guru, keterlibatan warga sekolah juga menunjukkan hubungan yang kuat dengan keadilan yang diterima (Guy, 2008).

Freiberg dan Stein menjelaskan bahwa school climate sebagai esensi sekolah yang sangat penting dalam menarik siswa untuk mencintai sekolah dan merasa nyaman. Penekanan baru pada pentingnya school climate ini diperkuat lebih lanjut oleh studi meta-analisis yang dilakukan oleh Wang et al. (1997), bahwa iklim sekolah sangat berpengaruh dalam peningkatan prestasi belajar siswa (Macneil et. Al, 2009). Procedural justice juga mensyaratkan bahwa kesempatan dan keadilan yang diberikan kepada siswa, akan menuntut siswa tersebut memperlakukan orang lain dengan baik dan andil. Maka dari itu, school climate pada siswa juga dapat mempengaruhi persepsi procedural justice siswa di sekolah.

Berdasarkan hasil hipotesis yang kedua membuktikan adanya pengaruh langsung antara procedural justice dengan citizenship behavior toward environment siswa secara signifikan. Hal ini berarti, persepsi procedural justice yang dimiliki siswa sangat positif, akan meningkatkan perilaku bijak siswa untuk menjaga lingkungan atau citizenship behavior toward environment.

Procedural justice merupakan persepsi siswa terhadap keadilan yang diterima dari interaksi yang ada di sekolah (Dipaola 2013). Seperti, siswa mendapat perlakuan adil di kelas saat pembelajaran, dengan begitu siswa akan merasa dirinya pantas untuk mendapatkan kesempatan yang sama. Pentingnya kesan keadilan pada diri seseorang, akan bendampak pada perilaku yang dilakukan. Maka dari itu, proses pembelajaran, aturan sekolah, dan perlakuan guru kepada siswa harus adil dan merata agar tidak timbul kecemburuan pada siswa.

Citizenship behavior toward environment merupakan perilaku siswa yang bersifat bebas sesuai keinginan sendiri, secara eksplisit tanpa mengharap reward formal sehingga efektif membantu kegiatan di lingkungan. Perilaku ini merupakan perilaku sukarela siswa yang tidak ditentukan dalam uraian tugas sekolah, sehingga 
siswa pun berupaya bekerja sama dengan sesama untuk menjadikan lingkungan sekolah yang berkelanjutan (Lamm E et. Al, 2013).

Konsep penting yang berkaitan dengan citizenship behavior adalah keadilan. Keadilan yang diterima seseorang akan menjadi suatu alasan untuk melakukan perilaku bijak (yaylaci, 2014). Salah satu yang mempengaruhi citizenship behavior siswa adalah persepsi tentang keadilan dalam sekolah, yaitu procedural justice. Didukung dengan pendapat Moorman (1991), yang menyatakan persepsi seseorang terhadap susana lingkungan ia tempat bekerja yang adil akan meningkatkan kepuasan kerja dan melakukan perilaku bijak dalam kesehariannya. Lalu Organ menambahkan bahwa untuk perubahan citizenship behavior pada siswa sejalan dengan procedural justice yang diterima siswa.

Hasil pengujian hipotesis ketiga, menunjukkan adanya pengaruh langsung antara school climate terhadap citizenship behavior toward environment siswa. Yang artinya, persepsi tentang school climate yang dimiliki siswa, dapat mempengaruhi perilaku bijak yang mengarah pada lingkungan atau citizenship behavior toward environment.

School climate yang baik akan membuat siswa senang dalam melakukaan kegiatan lingkungan di sekolah. Dengan perasaan yang nyaman berada di sekolah, siswa juga akan merasa ingin untuk menjaga lingkungan tanpa adanya perintah dari guru ataupun peraturan. Siswa akan memiliki citizenship behavior toward environment yang baik, dan membuat siswa bekerja secara sukarela untuk mecegah kerusakan lingkungan. Didukung dengan penelitian Michael D. \& Megan. T yang menunjukkan adanya hubungan positif antara school climate dengan citizenship behavior seseorang

Besarnya citizenship behavior di sekolah dan hubungannya dengan school climate penting untuk dipahami oleh organisasi sekolah. Untuk menanamkan perilaku positif seperti citizenship behavior toward environment, maka sekolah harus membuat suasana yang baik dalam pembelajaran. Hal ini agar persepsi siswa terhadap school climate mendukung terciptanya perilaku bijak dalam menjaga lingkungan. Siswa yang 
yang sigap dalam permasalahan lingkungan, akan memberikan timbal balik positif terhadap keefektifitas di sekolah. Karena, siswa melakukan pekerjaan yang tidak diwajibkan di sekolah, dan perilaku ini disebut sebagai "extra-role behavior"

Hasil pengujian hipotesis yang keempat, didapatkan bahwa terdapat pengaruh tidak langsung antara school climate terhadap citizenship behavior toward environment siswa melalui procedural justice. Dengan kata lain, seorang siswa yang memiliki school climate yang positif maka juga dapat meningkatkan citizenship behavior toward environment melalui procedural justice yang dimiliki.

Citizenship behavior toward environment akan terbentuk pada siswa ketika perlakuan yang didapat siswa di sekolah juga positif. Dengan school climate yang baik, akan mendukung siswa dalam menumbuhkan citizenship behavior toward environment dalam pengelolaan lingkungan. Selain itu, perlakuan yang diterima siswa juga akan mempengaruhi perilaku bijak siswa di sekolah. Siswa dengan procedural justice yang tinggi, akan merasa sangat senang mengerjakan banyak hal di sekolah tanpa perlu disuruh terlebih dahulu. Iklim yang baik dan perlakuan adil akan membuat siswa nyaman dan lebih aktif mengikuti kegiatan kebersihan sekolah. Siswa akan lebih peka terhadap permasalahan lingkungan, dan peduli terhadap lingkungan di sekolah. Siswapun akan melakukan hal untuk mengurangi kerusakan lingkungan, seperti membuang sampah pada tempatnya, ikut kegiatan lingkungan hidup, mendukung program.

\section{KESIMPULAN}

Berdasarkan dari hasil penelitian didapat beberapa temuan yaitu:

1. Terdapat pengaruh langsung antara school climate terhadap procedural justice siswa secara signifikan

2. Terdapat pengaruh langsung antara procedural justice terhadap citizenship behavior toward environment siswa secara signifikan 
3. Terdapat pengaruh langsung antara school climate terhadap citizenship behavior toward environment siswa secara signifikan

4. Terdapat pengaruh tidak langsung antara school climate terhadap citizenship behavior toward environment siswa melalui procedural justice secara signifikan

Berdasarkan temuan-temuan yang dijelaskan diatas, maka dapat disimpulkan bahwa untuk mengurangi variasi dari citizenship behavior toward environment siswa dapat mempertimbangkan variasi school climate dan procedural justice dengan meminimalkannya. Setiap siswa dapat memiliki citizenship behavior toward environment sesuai dengan school climate dan procedural justice yang dimilikinya. Procedural justice terdapat pengaruh tidak langsung terhadap citizenship behavior toward environment, sehingga procedural justice baik sebagai mediator variabel antara school climate dengan citizenship behavior toward environment.

\section{REFERENSI}

Barnes, K., Brynard, S., \& De Wet, C. (2012). The influence of school culture and school climate on violence in schools of the Eastern Cape Province. South African Journal of Education, 32(1), 69-82.

Beaudoin, H., \& Robrge, G. (2015). Student perceptions of school climate and lived bullying behaviours. Procedia-Social and Behavioral Sciences, 174, 322

Bradshaw, C. P., Wasdorp, T. E., Debnam, K. J., \& Johnson, S. L. (2014). Measuring School Climate in High Schools: A Focus on Safety, Engagement, and the Environment. Journal of School Health, 84(9), 593-604.

Cohen, J., Mccabe, E. M., \& Michelli, N. M. (2009). School Climate: Research, Policy, Practice, and Teacher Education. Teachers College Record, 111(1), 180-213. 
DeConinck, James B. (2010). The effect of organizational justice, perceived organizational support, and perceived supervisor support on marketing employees' level of trust. Jurnal of business research. 63. 1349-1355

Dipaola, M., \& Guy, S. (2009). The impact of organizational justice on climate and trust in high schools. Journal of School Leadership, 19(4), 382-405.

Dipaola, M., \& Tschannen-Moran, M. (2001). Organizational citizenship behavior in schools and its relationship to school climate. Journal of school Leadership, 11(5), 424-447.

Guy, S. L. (2008). Organizational justice perceptions in Virginia high schools: A study of its relationship to school climate and faculty trust.

Hudha, A. M., Husamah, \& Rahardjanto, A. (2019). Etika ingkungan (Teori dan Praktik Pembelajarannya). Malang: Penerbit Universitas Muhammadiyah Malang.

Jurewicz, M. M. (2004). Organizational citizenship behaviors of middle school teachers: A study of their relationship to school climate and student achievement.

Putrawan, I. M. (2015). Measuring New Environmental Paradigm Based on Students Knowledge about Ecosystem and Locus of Control. EURASIA Journal of Mathematics, Science and Technology Education, 11(2), 325-333

Ivancevich, John M., Robert Konopaske, M.T Matteson. (2014). Organizational behavior and management. Irwin: McGraw-Hill.

Lamm, E., Tosti-Kharas, J., \& Williams, E. G. Organizational Citizenship Behavior Toward the Environment Scale. Group \& Organization Management.

Lestari, A., Komala, R., \& Rusdi, R. (2019). Relationship between School Climate and Instructional Leadership with The Biology Teachers Justice. Indonesian Journal of Science and Education, 3(1), 34-42. 
Loukas, A. (2007). What is school climate. Leadership compass, 5(1), 1-3.

MacNeil, A. J., Prater, D. L., \& Busch, S. (2009). The effects of school culture and climate on student achievement. International Journal of leadership in Education, 12(1), 73-84

Moorman, R. H. (1991). Relationship between organizational justice and organizational citizenship behaviors: Do fairness perceptions influence employee citizenship?. Journal of applied psychology, 76(6), 845.

Naumann, S. E., \& Bennett, N. (2002). The effects of procedural justice climate on work group performance. Small Group Research, 33(3), 361-377.

Niehoff, B. P., \& Moorman, R. H. (1993). Justice as a mediator of the relationship between methods of monitoring and organizational citizenship behavior. Academy of Management journal, 36(3), 527-556.

Peguero, A. A., \& Bracy, N. L. (2015). School order, justice, and education: Climate, discipline practices, and dropping out. Journal of research on adolescence, 25(3), 412-426

Reaves, S., McMahon, S. D., Duffy, S. N., \& Ruiz, L. (2018). The test of time: A meta-analytic review of the relation between school climate and problem behavior. Aggression and violent behavior, 39, 100-108.

Sari, P. N. (2017). Analisis pengelolaan sampah padat di kecamatan Banuhampu kabupaten Agam. Jurnal Kesehatan Masyarakat Andalas, 10(2), 157-165.

Simbolon, B. R. (2010). Paket Materi Pembelajaran Inkuiri dalam Pendidikan Lingkungan Hidup untuk Meningkatkan Perilaku Berwawasan Lingkungan Siswa SD di Jakarta. Jurnal Pendidikan Lingkungan dan Pembangunan Berkelanjutan. 9 (2):1-20. 
Simarmata, B., Daulae, A. H., \& Raihana, R. (2018). Hubungan tingkat pengetahuan lingkungan hidup dengan sikap peduli lingkungan siswa. Jurnal Pelita Pendidikan, 6(4), 204-210

Suryanda, A., Miarsyah, M., \& Septiani, D. (2020). Pembentukan Perilaku Tanggung Jawab Lingkungan melalui Keikutsertaan Siswa SMA dalam Kegiatan Ekstrakurikuler Kelompok Pecinta Alam. Quagga: Jurnal Pendidikan dan Biologi, 12(2), 94-103.

Tastan, M., \& Yilmaz, K. (2008). Organizational citizenship and organizational justice scales' adaptation to Turkish. Egitim ve Bilim, 33(150), 87.

T.R Tyler \& A. Mentovich, (2013) Mecanisms of legal effect : Theories of procedural justice, (New York: PHLR Methods Monograph Series.

Vey, M. A., \& Campbell, J. P. (2004). In-Role or Extra-Role Organizational Citizenship Behavior: Which Are We Measuring? Human Performance, 17(1), 119-135.

Zapata-Phelan, C. P., Colquitt, J. A., Scott, B. A., \& Livingston, B. (2009). Procedural justice, interactional justice, and task performance: The mediating role of intrinsic motivation. Organizational behavior and human decision processes, 108(1), 93-105. 